\title{
Sensitivity Analysis for Influence Parameters of Rail Corrugation Characteristics in Metro Straight Section
}

\author{
Zhiqiang Wang ${ }^{1 *}$, Zhenyu Lei ${ }^{1}$ \\ 1 Institute of Rail Transit, Tongji University, Shanghai, China \\ * Corresponding author's e-mail: 1733359@tongji.edu.cn
}

\begin{abstract}
Based on the theory of friction self-excited vibration and the measured data of rail corrugation, the cause of rail corrugation in metro straight section was analyzed. Then, using the stochastic finite element method, the sensitivity of each parameter to rail corrugation was studied by selecting the elastic modulus $E_{1}$ and density $\rho_{1}$ of the wheelrail material, the elastic modulus $E_{2}$ and density $\rho_{1}$ of the track slab material, the wheel-rail coefficient of friction $f$, the fastener vertical stiffness $K$ and vertical damping $C$, the wheel-rail longitudinal relative slip $s$ as the random parameters. The results show that under the support of Cologne egg fastener track, the characteristic frequency of friction self-excited vibration of wheel-rail system is close to the characteristic frequency of measured corrugation, indicating that the occurrence of rail corrugation is related to the friction self-excited vibration of wheel-rail system under the condition of saturated creep force. The parameter sensitivity analysis illustrates that the influence degree of each random parameter on the real part $\alpha_{i}$ of complex eigenvalue is $E_{1}>\rho_{1}>C>E_{2}>\rho_{2}>f>K>s$ in turn. $E_{1}, C$ and $s$ are positively correlated with the real part $\alpha_{i}$ of complex eigenvalue, while the remaining 5 parameters are negatively correlated with the real part $\alpha_{i}$ of complex eigenvalue. Therefore, appropriate decrease of $E_{1}, C$ and $s$, and increase of $\rho_{1}, E_{2}, \rho_{2}, f$ and $K$ can play a positive role in the control of rail corrugation.
\end{abstract}

Keywords: metro; rail corrugation; friction self-excitation; stochastic finite element; sensitivity analysis.

\section{INTRODUCTION}

Rail corrugation is a kind of periodic wavy irregularity occurring on the running surface of rail, which widely exists in metro lines all over the world. With the increase of track structure types and vehicle operation speed, the forms of rail corrugation are gradually diversified, and its generation mechanism is becoming more and more complex. When the vehicle passes through the rail corrugation section, it will induce abnormal vibration and noise in the wheel-rail system, affect the comfort of passengers and the living environment of residents along the line, and cause fatigue damage to the vehicle and track parts, posing a threat to the operation safety. There are many influence factors of rail corrugation and the influence degree of each factor is quite different. How to effectively identify the sensitive influence parameters of rail corrugation and take targeted measures to control rail corrugation are always the technical problems that need to be solved in the railway industry.

Rail corrugation has a history of more than 120 years since it was reported. The research on rail corrugation has been continuously refined and deepened. The literature [1-3] reviewed the phenomenon of rail corrugation around the world at that time, mainly including the characteristics, causes and countermeasures of rail corrugation. In literature [4], the research on the short pitch corrugation on the straight track was mainly reviewed, and the cause of such corrugation was discussed. The literature [5] investigated the influence of sleeper spacing on the increase of rail corrugation in the Bilbao metro curve section, and found that rail corrugation did not increase when sleeper spacing was reduced to half of the original one. Combined with wheelset-track-absorber dynamics, rolling 
contact mechanics and wear theory, the literature [6] analyzed the influence of rail absorber on the growth of short pitch corrugation, and the results showed that the rail absorber could effectively suppress the short pitch corrugation associated with the Pinned-Pinned resonance. The literature [7] explored the influence of the stiffness of the rail pad on rail corrugation in the metro line. The results indicated that the soft rail pad could reduce the growth of rail corrugation and eliminate a kind of corrugation wavelength generated when using the hard rail pad. The literature [8] studied the influence of the stiffness of the rail pad on the occurrence of rail corrugation by using the friction self-excited vibration model of wheel-rail system, and found that the occurrence probability of rail corrugation decreased with the increase of the stiffness of the rail pad. The conclusion in the literature [8] is contrary to that in the literature [7], which may be related to the offset of vehicle-track resonance frequency caused by the use of air springs in metro vehicles in recent years [9]. In literature [10], the generation mechanism of rail corrugation was analyzed in frequency domain and time domain by using vehicle-track coupling model and corrugation evaluation model, and the development characteristics of rail corrugation were studied by using corrugation growth rate. The literature [11] revealed the generation mechanism of rail corrugation on the metro track with Pioneer fasteners through numerical simulation, analyzed the main influence factors of rail corrugation, and found that increasing the damping coefficient of rubber pad to more than 0.0001 could significantly reduce rail corrugation. The literature [12] studied the numerical feasibility of self-excited vibration prediction to explain the formation of rutting corrugation without initial rail roughness excitation. The literature [13] investigated the possible solutions of train-track excessive dynamic interaction caused by rail corrugation in the metro track through numerical analysis and field tests. The results demonstrated that in the studied track system, the stiffness of the rail pad was the key factor affecting wheel-rail contact force. The literature [14] analyzed the influence of different track structure parameters and vehicle operation speed on the generation and development of rail corrugation on the straight track by using the control variable method. Based on the wheel-rail coupling effect, a practical model for predicting the growth of rail corrugation was proposed in the literature [15], the main cause of rail corrugation was studied, and the parameter analysis was carried out. The results illustrated that the track super-harmonic resonance under the direct excitation of vehicle promoted the formation of rail corrugation, and the adjustment of fastener support stiffness and sleeper spacing would lead to the fluctuation of corrugation wavelength and wear rate.

It can be seen from the above literature investigation that so far the research on rail corrugation mainly focuses on the analysis of the formation reasons and the influence parameters. In terms of the causes of rail corrugation, the friction self-excited vibration mechanism of wheel-rail system under saturated creep force proposed by Chen's team [16-18] can explain most existing rail corrugation phenomena and accurately capture the characteristic frequencies of rail corrugation. In the analysis of influence parameters of rail corrugation, most literatures adopt the deterministic analysis method, that is, only changing the value of a certain influence parameter each time, and keeping the other influence parameters unchanged, so as to analyze the influence of this parameter on rail corrugation. In this method, it is difficult to consider the influence of continuous change of a parameter on rail corrugation, and when multiple parameters are changed at the same time, the influence degree of each parameter on rail corrugation cannot be distinguished, so the analysis has certain blindness. In view of that, the cause of rail corrugation on the actual straight line is analyzed by using the theory of friction self-excited vibration combined with the field measured corrugation data. Then, based on the stochastic finite element method, the elastic modulus and density of wheel-rail material and track slab material, the wheel-rail coefficient of friction, the fastener vertical stiffness and vertical damping, the wheel-rail longitudinal relative slip are selected as the random parameters to explore the sensitivity of each parameter to rail corrugation, and the correlation between each parameter and the occurrence of rail corrugation is obtained, so as to provide reference for the prevention and treatment of rail corrugation. The novelty of this work is that the stochastic finite element method employed can not only consider the influence of continuous variation of a single parameter on rail corrugation, but also consider the influence of each parameter on rail corrugation in the case of continuous variations of multiple parameters. 


\section{MEASURED CORRUGATION ANALYSIS}

The measured corrugation section is located in a metro straight line in Shanghai. The track fastener type is Cologne egg fastener, the vehicle type is metro type-A vehicle, and the operating speed is $60 \mathrm{~km} / \mathrm{h}$. The CAT (Corrugation Analysis Trolley) detection equipment is used to measure the corrugation section and the corresponding mileage curves of rail surface irregularities are obtained, as shown in Fig. 1(a). Further, by performing spectrum transformation on the curve, the one-third octave wavelength spectrum of rail surface irregularity can be obtained, as shown in Fig. 1(b). The field picture of rail corrugation is shown in Fig. 1(c).

According to Fig. 1(b), the characteristic wavelengths of left and right rails in the measured straight section are all $100 \mathrm{~mm}$. Since the operating speed of vehicle in this section is $60 \mathrm{~km} / \mathrm{h}$, the characteristic frequency of rail corrugation can be calculated using Eq. (1) as $166.7 \mathrm{~Hz}$.

$$
\omega=\frac{1000 v}{3.6 \lambda}
$$

Where: $\omega$ is the characteristic frequency of rail corrugation, $\mathrm{Hz} ; v$ is the vehicle speed, $\mathrm{km} / \mathrm{h} ; \lambda$ is the wavelength of rail corrugation, $\mathrm{mm}$.

\section{CAUSE ANALYSIS OF RAIL CORRUGATION}

\section{Friction coupling model of wheel-rail system}

The measured section is located near the metro exit, the motor car is in the traction state, the creep force is large, and the wheel may slide. It is assumed that at this time the wheel-rail creep force tends to saturation, that is, the creep force is equal to the product of the wheel-rail normal force and the coefficient of friction. When the vehicle runs on a straight track, the lateral displacement amount of the wheelset is small, and the contact relationships between the left and right wheels and rails are almost the same, thus, only the wheel-rail relationship on one side of the wheelset is considered in this section. Based on the theory of friction self-excited vibration, the friction coupling model of wheel-rail system is established, as shown in Figure 2. The model consists of the wheel, rail, spring-damping elements and track slab. The tangential direction of the wheel and the rail is coupled by friction, and the normal direction is connected by hard contact. The rail and the track slab are connected by the spring-damping element to simulate the Cologne egg fastener. The track slab is also connected to the foundation by the spring-damping element to simulate the supporting action of the foundation. In this model, the contact point between the
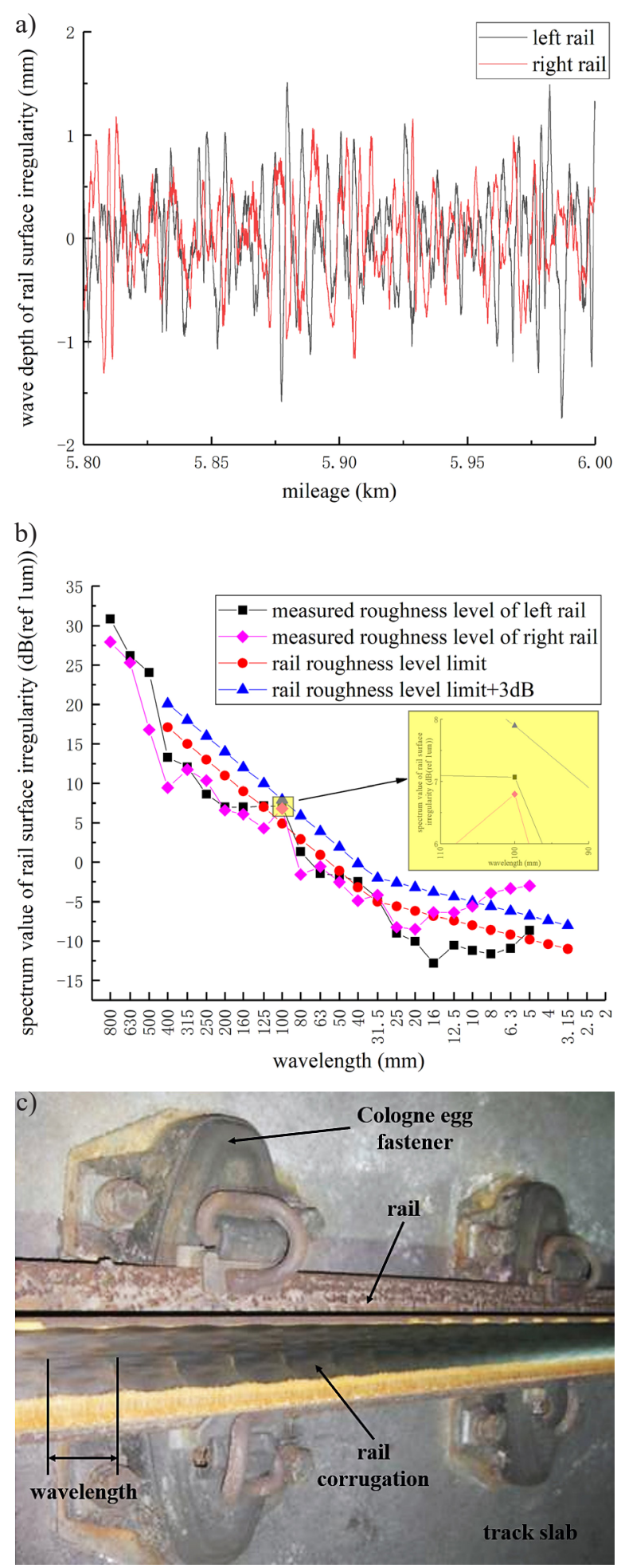

Fig. 1. Measured rail corrugation; a) Mileage curves of rail surface irregularities; b) One-third octave wavelength spectrums of rail surface irregularities; c) Field picture of rail corrugation 


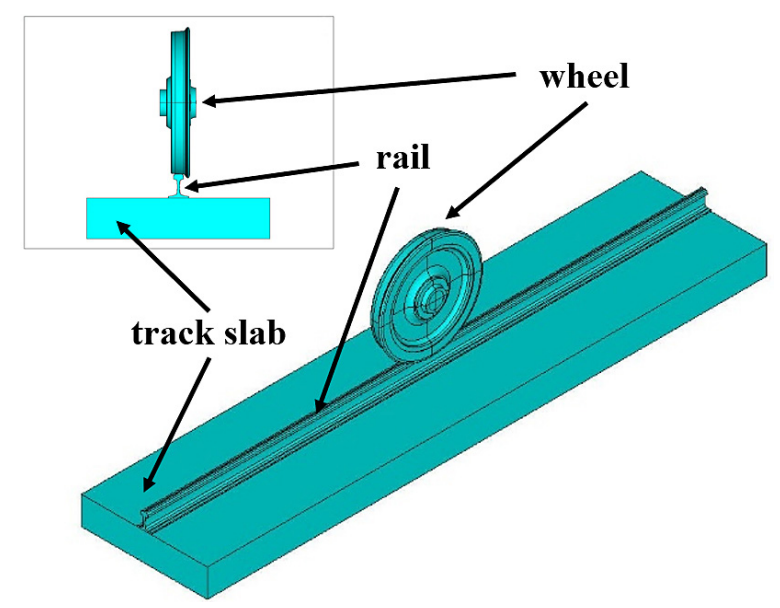

Fig. 2. Friction coupling model of wheel-rail system

wheel and the rail is located near the central position of the rail head, as shown in Figure 2. The boundary and load conditions of the model are shown in Figure 3, where $F_{V}$ represents the vertical force of axle box, as the lateral force of axle box is very small in the straight line, it is ignored; $s$ represents the wheel-rail longitudinal relative slip. There are 528113 nodes and 318572 elements in the whole model.

\section{Model parameters}

In the friction coupling model of wheel-rail system established above, the wheel tread is LM wear type and the wheel diameter is $840 \mathrm{~mm}$; the rail type is $60 \mathrm{~kg} / \mathrm{m}$ and the length is $6 \mathrm{~m}$; the section size of track slab is $1350 \mathrm{~mm} \times 300 \mathrm{~mm}$ and the length is consistent with the rail length. The density of wheel-rail material is $7800 \mathrm{~kg} / \mathrm{m}^{3}$, the elastic modulus is $2.1 \times 10^{11} \mathrm{~Pa}$, and the Poisson's ratio is 0.3 ; the density of track slab material is 2 $400 \mathrm{~kg} / \mathrm{m}^{3}$, the elastic modulus is $3.25 \times 10^{10} \mathrm{~Pa}$, and the Poisson's ratio is 0.24 [19]. The fastener spacing is $0.6 \mathrm{~m}$ and the wheel-rail coefficient of friction is 0.35 . The vertical force $F_{V}$ of axle box is calculated by the dynamics software UM (Universal Mechanism) [20]. Firstly, the vehicle-track coupling model is constructed according to the actual line situation, and then the vertical force of axle box when the vehicle passes through the target line section is obtained through simulation, and its value is $69000 \mathrm{~N}$. The wheel-rail longitudinal relative slip is set as $65.42 \mathrm{~mm}$ [21]. The measured vertical stiffness and damping of Cologne egg fastener are $1.207 \times 10^{7} \mathrm{~N} / \mathrm{m}$ and $1361.12 \mathrm{Ns} / \mathrm{m}$ respectively, the lateral stiffness and damping are $7.58 \times 10^{6} \mathrm{~N} / \mathrm{m}$ and $974.27 \mathrm{Ns} / \mathrm{m}$ respectively; the supporting stiffness and damping of foundation are $1.7 \times 10^{8} \mathrm{~N} / \mathrm{m}$ and $3.1 \times 10^{4} \mathrm{Ns} / \mathrm{m}$ respectively [22].

\section{RESULTS AND ANALYSIS}

By using the complex eigenvalue analysis method, the friction self-excited vibration frequency and corresponding vibration mode of wheel-rail system in the Cologne egg fastener section of the measured line can be obtained, as shown in Figure 4. In this paper, the real part $\alpha_{i}$ of complex eigenvalue is used as the index to judge the stability of the system. When $\alpha_{i}>0$, the system gradually tends to be unstable. The larger the real part of complex eigenvalue, the greater the possibility of self-excited vibration of the system at the corresponding frequency [23]. If the real part of complex eigenvalue is

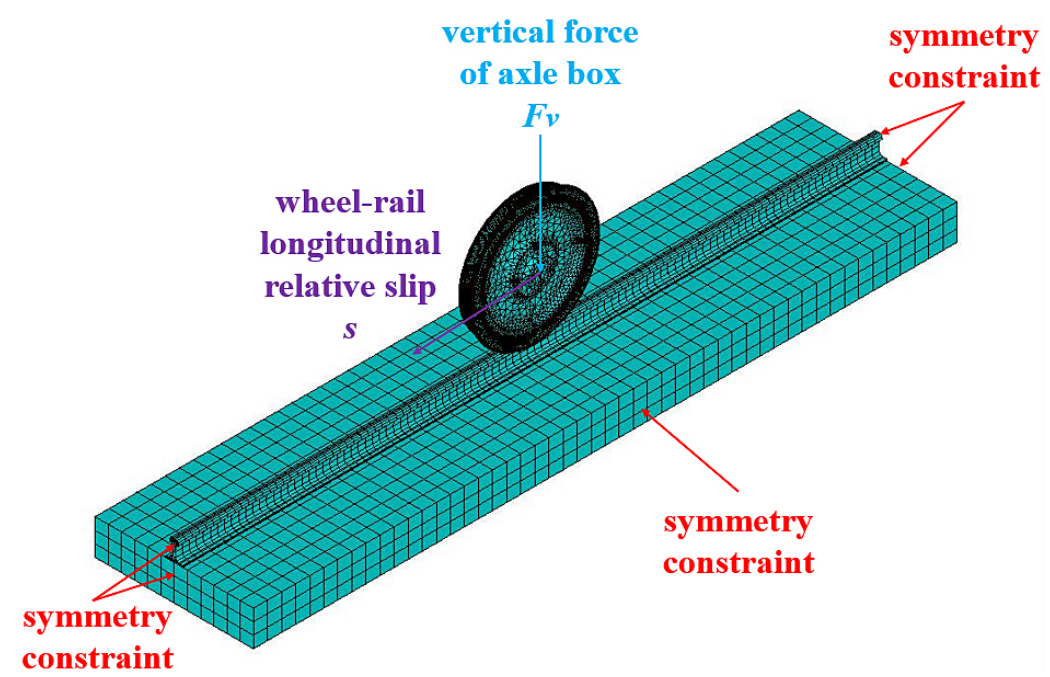

Fig. 3. Model boundary and load conditions 


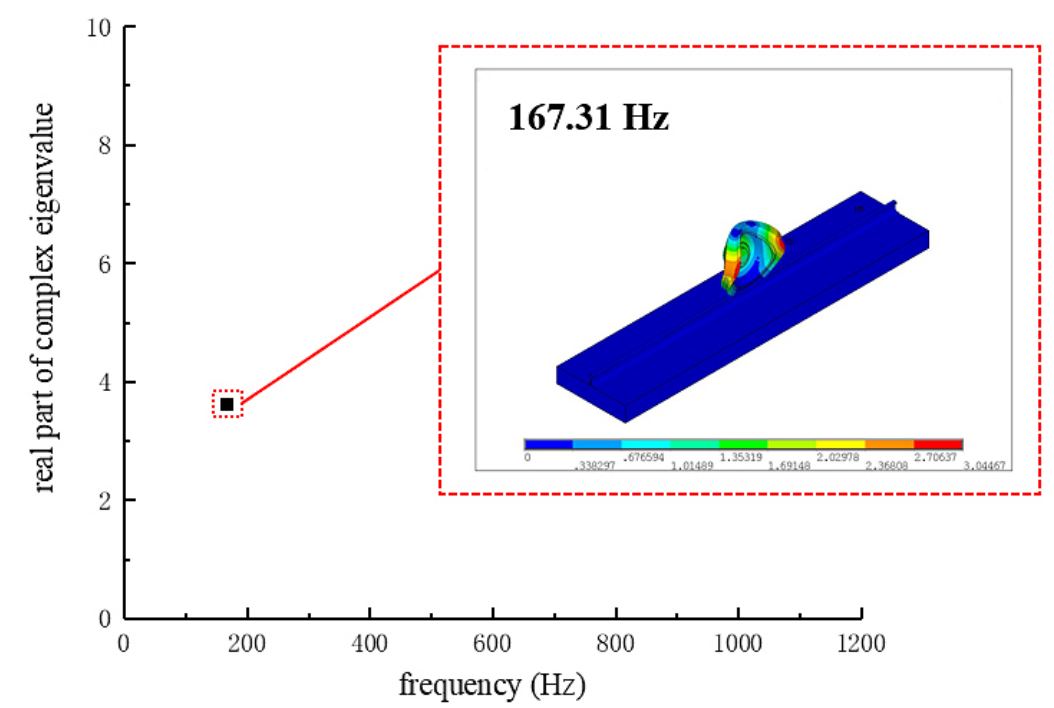

Fig. 4. Friction self-excited vibration frequency and vibration mode of wheel-rail system

too small, the damping of the track structure itself is enough to overcome a small amount of unstable vibration. At this time, the probability of self-excited vibration of wheel-rail system is very low and can be ignored.

It can be seen from Figure 4 that under the support of Cologne egg fastener track, the characteristic frequency of friction self-excited vibration of wheel-rail system is $167.31 \mathrm{~Hz}$, which is close to the characteristic frequency of measured corrugation of $166.7 \mathrm{~Hz}$, which shows that the measured corrugation is mainly caused by the friction self-excited vibration of wheel-rail system under the condition of saturated creep force.

\section{PARAMETER SENSITIVITY ANALYSIS}

\section{Statistical characteristics of random parameters}

The elastic modulus $E_{1}$ and density $\rho_{1}$ of the wheel-rail material, the elastic modulus
$E_{2}$ and density $\rho_{2}$ of the track slab material, the wheel-rail coefficient of friction $f$, the fastener vertical stiffness $K$ and vertical damping $C$, and the wheel-rail longitudinal relative slip $s$ are selected as random parameters without considering the correlation between various variables. The distribution types and statistical characteristics of each random parameter are shown in Table $1[22,24]$.

The ANSYS-PDS stochastic analysis module [25-27] is mainly used to calculate the influence of random parameters on rail corrugation in this paper. The random parameter information is input into the stochastic analysis module of the ANSYS software, and the real part $\alpha_{i}$ of complex eigenvalue is taken as the analysis target. The Monte Carlo method and Latin Hyper method are selected as the probabilistic analysis methods. The statistical characteristics of the real part of complex eigenvalue, which is the evaluation index of the occurrence trend of rail corrugation, can be acquired

Table 1. Distribution types and statistical characteristics of random parameters

\begin{tabular}{|c|c|c|c|c|c|}
\hline Parameter & Distribution type & Mean value & Standard value & $\begin{array}{c}\text { Minimum limit } \\
\text { value }\end{array}$ & $\begin{array}{c}\text { Maximum limit } \\
\text { value }\end{array}$ \\
\hline$E_{1}(\mathrm{~Pa})$ & Gaussian & $2.1 \times 10^{11}$ & $0.05 E_{1}$ & $1.995 \times 10^{11}$ & $2.205 \times 10^{11}$ \\
\hline$\rho_{1}\left(\mathrm{~kg} / \mathrm{m}^{3}\right)$ & Gaussian & 7800 & $0.05 \rho_{1}$ & 7410 & 8190 \\
\hline$E_{2}(\mathrm{~Pa})$ & Gaussian & $3.25 \times 10^{10}$ & $0.05 E_{2}$ & $3.0875 \times 10^{10}$ & $3.4125 \times 10^{10}$ \\
\hline$\rho_{2}\left(\mathrm{~kg} / \mathrm{m}^{3}\right)$ & Gaussian & 2400 & $0.05 \rho_{2}$ & 2280 & 2520 \\
\hline$f$ & Uniform & 0.35 & - & 0.05 & 0.65 \\
\hline$K(\mathrm{~N} / \mathrm{m})$ & Uniform & $1.207 \times 10^{7}$ & - & $8.07 \times 10^{6}$ & $5.207 \times 10^{7}$ \\
\hline$C(\mathrm{Ns} / \mathrm{m})$ & Uniform & 1361.12 & - & 861.12 & 6361.12 \\
\hline$s(\mathrm{~mm})$ & Uniform & 65.42 & - & 25.42 & 105.42 \\
\hline
\end{tabular}


by the probabilistic design analysis, which can be used as the basis of the sensitivity analysis of random parameters.

\section{Sensitivity analysis of random parameters}

Sensitivity analysis can be used to evaluate the influence degree of random factors on structural responses. In this paper, the Spearman rank-order correlation coefficient [28] is used to indirectly express the sensitivity of parameters. The Spearman rank-order correlation coefficient can be used to measure the strength of the relationship between variables. If the calculated coefficient is close to 1 or -1 , it is considered that the input variable has significant influence on the output variable; if the calculated coefficient approaches 0 , the influence is considered weak. If the coefficient is positive, the value of the output variable increases as the input variable increases; if the coefficient is negative, it means that the value of the output variable decreases as the input variable increases.

The sensitivity of the real part $\alpha_{i}$ of complex eigenvalue to each random parameter is shown in Table 2. It can be obtained through analysis that:

1) The first two parameters that have great influence on the real part $\alpha_{i}$ of complex eigenvalue are $E_{1}$ and $\rho_{1}$ respectively, indicating that the elastic modulus and density characteristics of the wheel-rail material have an important influence on the occurrence trend of rail corrugation; the other parameters are $C>E_{2}>\rho_{2}>f>$ $K>s$ in turn.

2) The sensitivities of $E_{1}, C$ and $s$ are positive, indicating that $E_{1}, C$ and $s$ are positively correlated with the real part $\alpha_{i}$ of complex eigenvalue, while the sensitivities of the other 5 parameters are negative, indicating that these parameters are negatively correlated with the real part $\alpha_{i}$ of complex eigenvalue. Since reducing the real part $\alpha_{i}$ of complex eigenvalue can effectively suppress the unstable vibration of the system and thus control the occurrence of rail corrugation, appropriately reducing $E_{1}$, $C$ and $s$, and increasing $\rho_{1}, E_{2}, \rho_{2}, f$ and $K$ can play a positive role in the control of rail corrugation. The scatter diagrams of the real part $\alpha_{i}$ of complex eigenvalue changing with random parameters are shown in Figure 5.

\section{CONCLUSIONS}

Based on the theory of friction self-excited vibration and the field measured data, the cause of rail corrugation on the straight section is analyzed in this paper. Then, using the stochastic finite element method, by selecting the elastic moduli and densities of wheel-rail material and track slab material, the wheel-rail coefficient of friction, the fastener vertical stiffness and vertical damping, the wheelrail longitudinal relative slip as random parameters, the sensitivity of each parameter to the influence of rail corrugation is studied, so as to provide reference for the prevention and treatment of rail corrugation. The following conclusions are drawn:

1) Under the support of Cologne egg fastener track, the characteristic frequency of friction self-excited vibration of wheel-rail system is $167.31 \mathrm{~Hz}$, which is close to the characteristic frequency of measured corrugation of 166.7 $\mathrm{Hz}$, indicating that the measured corrugation is mainly caused by the friction self-excited vibration of wheel-rail system under the condition of saturated creep force.

2) The parameter sensitivity analysis shows that the influence degree of each random parameter on the real part $\alpha_{i}$ of complex eigenvalue is $E_{1}>\rho_{1}>C>E_{2}>\rho_{2}>f>K>s$ in turn.

3) $E_{1}, C$ and $s$ are positively correlated with the real part $\alpha_{i}$ of complex eigenvalue, while the other 5 parameters are negatively correlated with the real part $\alpha_{i}$ of complex eigenvalue. Therefore, properly reducing $E_{1}, C$ and $s$, and increasing $\rho_{1}, E_{2}, \rho_{2}, f$ and $K$ can have a positive effect on the control of rail corrugation.

\section{Acknowledgements}

This work was financially supported by the National Natural Science Foundation of China, and the project number is 11772230 .

Table 2. Sensitivities of real part $\alpha_{i}$ of complex eigenvalue

\begin{tabular}{|c|c|c|c|c|c|c|c|c|}
\hline \multirow{2}{*}{$\begin{array}{c}\text { Analysis } \\
\text { target }\end{array}$} & \multicolumn{8}{|c|}{ Sensitivity of each random parameter } \\
\cline { 2 - 9 } & $E_{1}$ & $\rho_{1}$ & $E_{2}$ & $\rho_{2}$ & $f$ & $K$ & $C$ & $s$ \\
\hline$\alpha_{i}$ & 0.7088 & -0.7003 & -0.0406 & -0.0361 & -0.0334 & -0.0160 & 0.0471 & 0.0078 \\
\hline
\end{tabular}


a)

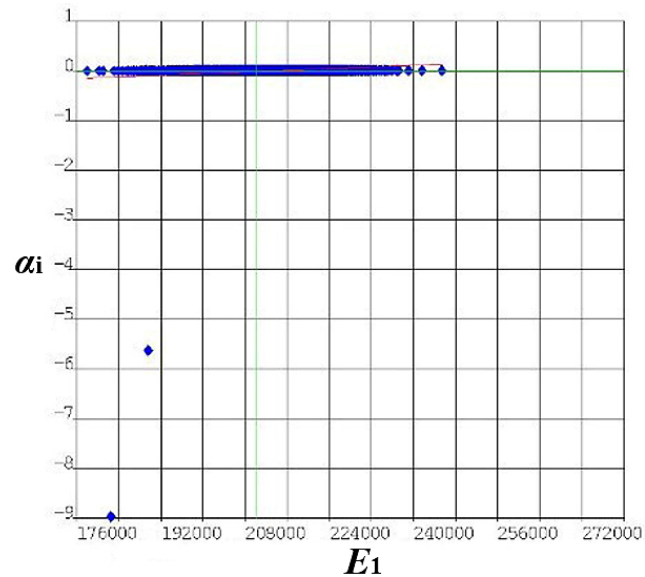

c)

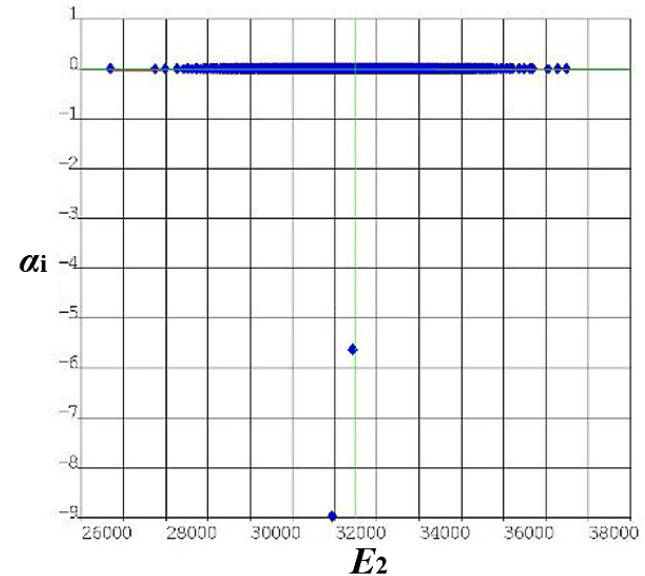

e)

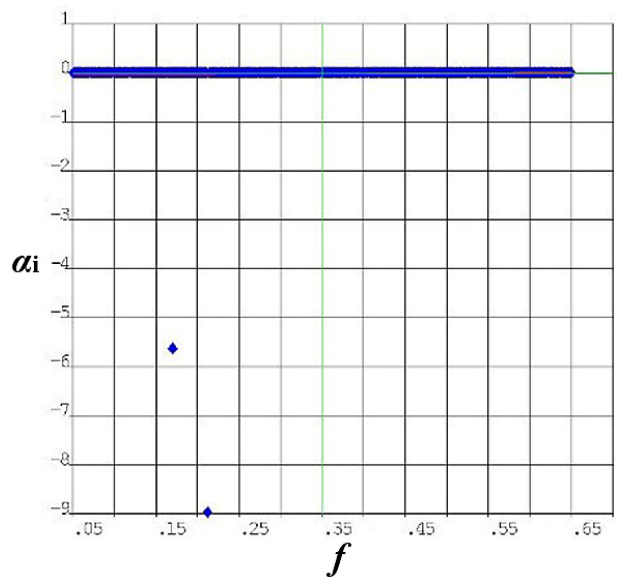

g)

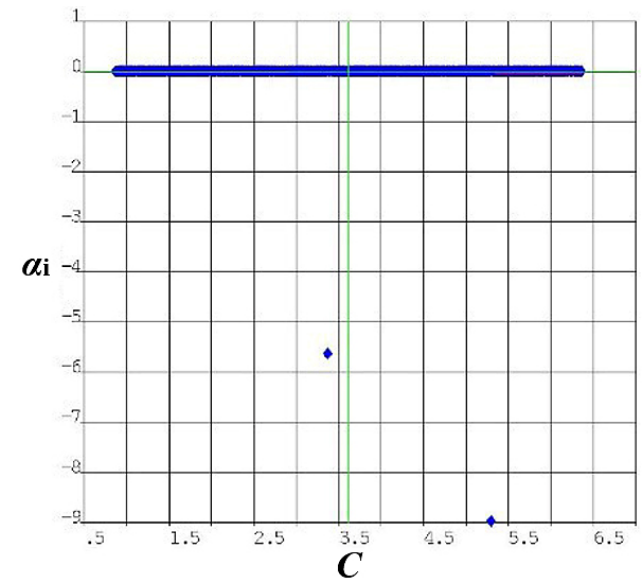

b)

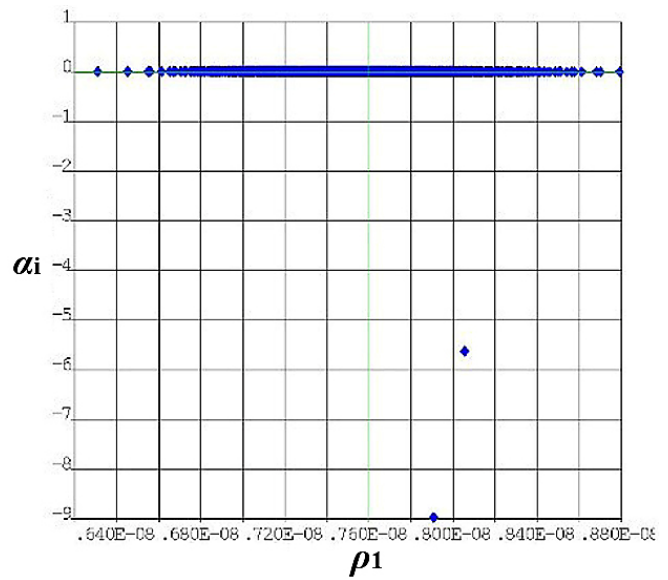

d)

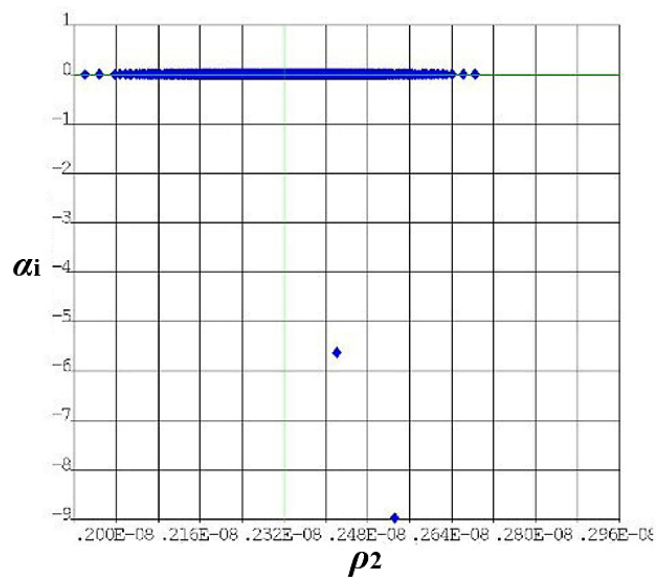

f)

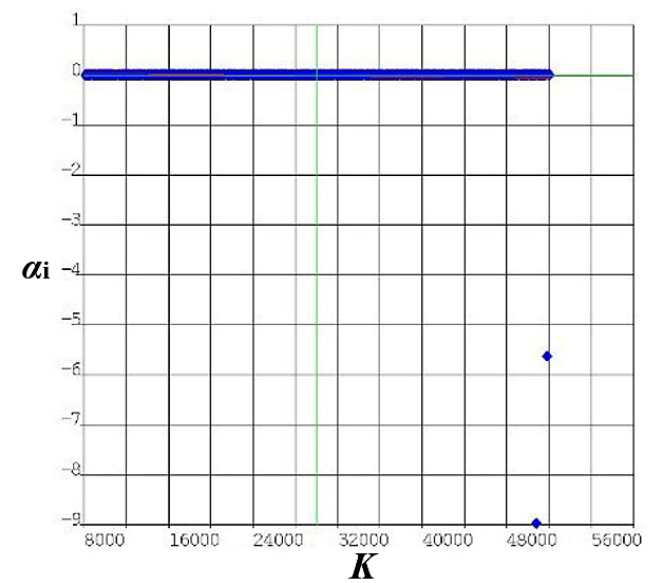

h)

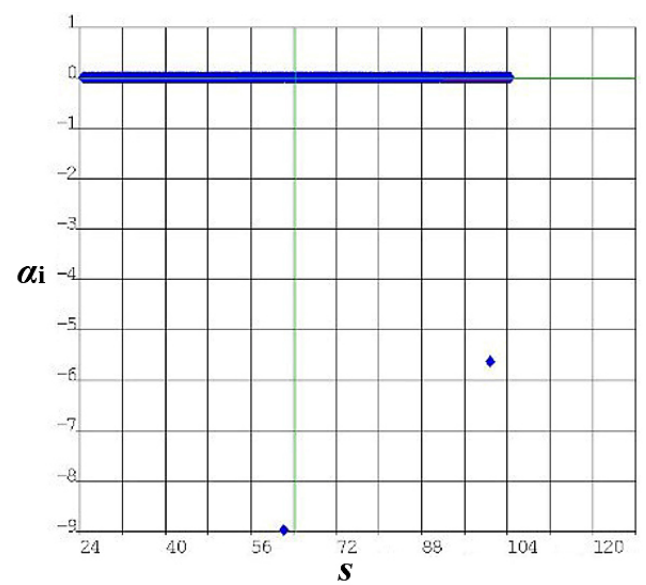

Fig. 5. Scatter diagrams of $\alpha_{i}$ and each random parameter; a) $E_{1}$, b) $\rho_{1}$, c) $E_{2}$, d) $\rho_{2}$, e) $f$, f) $K$, g) $C$, h) $s$ 


\section{REFERENCES}

1. Grassie S.L., Kalousek J. Rail corrugation: characteristics, causes and treatments. Proceedings of the Institution of Mechanical Engineers, Part F: Journal of Rail and Rapid Transit. 1993;207(1):57-68.

2. Sato Y., Matsumoto A., Knothe K. Review on rail corrugation studies. Wear. 2002;253(1-2):130-139.

3. Grassie S.L. Rail corrugation: characteristics, causes, and treatments. Proceedings of the Institution of Mechanical Engineers, Part F: Journal of Rail and Rapid Transit. 2009;223(6):581-596.

4. Oostermeijer K.H. Review on short pitch rail corrugation studies. Wear. 2008;265(9-10):1231-1237.

5. Vadillo E.G., Tárrago J., Zubiaurre G.G., Duque C.A. Effect of sleeper distance on rail corrugation. Wear. 1998;217(1):140-145.

6. Wu T.X. Effects on short pitch rail corrugation growth of a rail vibration absorber/damper. Wear. 2011; 271(1-2):339-348.

7. Egana J.I., Vinolas J., Seco M. Investigation of the influence of rail pad stiffness on rail corrugation on a transit system. Wear. 2006;261(2):216-224.

8. Chen, G.X., Qian, W.J., Mo J.L., Zhu M.H. Influence of the rail pad stiffness on the occurrence propensity of rail corrugation. Journal of Vibration Engineering and Technologies. 2016;4(5):455-458.

9. Liu X.G., Wang P. Investigation of the generation mechanism of rail corrugation based on friction induced torsional vibration. Wear. 2021;468469:203593.

10. Lei Z.Y., Wang Z.Q. Generation mechanism and development characteristics of rail corrugation of Cologne egg fastener track in metro. KSCE Journal of Civil Engineering. 2020;24(6):1763-1774.

11. Wu B.W., Chen G.X., Lv J.Z., Zhu Q., Kang X. Generation mechanism and remedy method of rail corrugation at a sharp curved metro track with Vanguard fasteners. Journal of Low Frequency Noise Vibration and Active Control. 2020;39(2):368-381.

12. El Beshbichi O., Wan C., Bruni S., Kassa E. Complex eigenvalue analysis and parameters analysis to investigate the formation of railhead corrugation in sharp curves. Wear. 2020;450-451:203150.

13. Song X.L., Qian Y., Wang K.Y., Liu P.F. Effect of rail pad stiffness on vehicle-track dynamic interaction excited by rail corrugation in metro. Transportation Research Record. 2020;2674(6):225-243.

14. Wang Z.Q., Lei Z.Y. Parameter influences on rail corrugation of metro tangential track. International Journal of Structural Stability and Dynamics. 2021;21(3):2150034.

15. Yin X.X., Wei X.K., Zheng H.C. Applying system dynamics of discrete supported track to analyze the rail corrugation causation on curved urban railway tracks. Discrete Dynamics in Nature and Society. 2021;9958163.

16. Chen G.X., Zhou Z.R., Ouyang H., Jin X.S., Zhu M.H., Liu Q.Y. A finite element study on rail corrugation based on saturated creep force-induced selfexcited vibration of a wheelset-track system. Journal of Sound and Vibration. 2010;329(22):4643-4655.

17. Cui X.L., Chen G.X., Zhao J.W., Yan W.Y., Ouyang H., Zhu M.H. Field investigation and numerical study of the rail corrugation caused by frictional self-excited vibration. Wear. 2017;376(B):1919-1929.

18. Chen G.X., Zhang S., Wu B.W., Zhao X.N., Wen Z.F., Ouyang H., Zhu M.H. Field measurement and model prediction of rail corrugation. Proceedings of the Institution of Mechanical Engineers Part F-Journal of Rail and Rapid Transit. 2020;234(4):381-392.

19. Cui X.L., Qian W.J., Zhang Q., Yang H.G., Chen G.X., Zhu M.H. Forming mechanism of rail corrugation of a straight track section supported by Cologne-egg fasteners. Journal of Vibration and Shock. 2016;35(13):114-118+152.

20. Wang Z.Q., Lei Z.Y. Analysis of influence factors of rail corrugation in small radius curve track. Mechanical Sciences. 2021;12:31-40.

21. Chen G.X. Friction-induced vibration of a railway wheelset-track system and its effect on rail corrugation. Lubricants. 2020;8,18.

22. Li X. Study on the mechanism of rail corrugation on subway track. PhD Dissertation, Southwest Jiaotong University, Chengdu, 2012.

23. AbuBakar A.R., Ouyang H. Complex eigenvalue analysis and dynamic transient analysis in predicting disc brake squeal. International Journal of Vehicle Noise and Vibration. 2006;2(2):143-155.

24. Li W. Study on root cause of metro rail corrugation and its influence on behavior of vehicle-track system. PhD Dissertation, Southwest Jiaotong University, Chengdu, 2015.

25. Lei Z.Y., Liu M. Waterproofness optimization for elastic rubber gaskets in shield tunnels with random parameters. Applied Mathematics and Mechanics. 2017;38(8):899-910.

26. Lei Z.Y., Liu M. Sensitivity analysis of water-proof performance of elastic rubber gasket in shield tunnel. Journal of Tongji University (Natural Science). 2017;45(3):336-341.

27. Lei Z.Y., Wang Z.Q., Jiang Z. Stress relaxation characteristics of rubber gasket under effect of random parameters. Journal of Tongji University (Natural Science). 2019;47(4):535-539.

28. Wang T. Infrared small target detection based on Spearman rank correlation coefficient. Science Technology and Engineering. 2017;17(2):234-238. 